\title{
How to improve the adenoma detection rate in colorectal cancer screening? Clinical factors and technological advancements
}

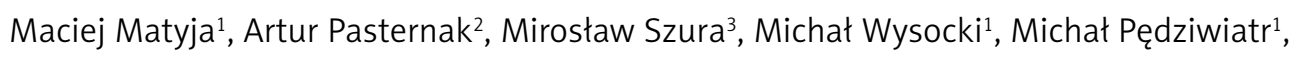
Kazimierz Rembiasz ${ }^{1}$

\begin{abstract}
${ }^{1} 2^{\text {nd }}$ Department of General Surgery, Jagiellonian University Medical College, Krakow, Poland

${ }^{2}$ Department of Anatomy, Jagiellonian University Medical College, Krakow, Poland ${ }^{3}$ Department of Experimental and Clinical Surgery, Jagiellonian University Medical College, Krakow, Poland
\end{abstract}

Submitted: 7 January 2018

Accepted: 15 February 2018

Arch Med Sci 2019; 15, 2: 424-433

DOI: https://doi.org/10.5114/aoms.2018.74863

Copyright (c) 2018 Termedia \& Banach

\begin{abstract}
Introduction: Colonoscopy has been widely regarded as the gold standard in colorectal cancer (CRC) screening. Within recent years different endoscopic imaging techniques have been introduced to improve the quality of colonoscopy. The adenoma detection rate (ADR) is the single most important quality indicator for colonoscopy. The aim of this study was to evaluate the quality of CRC screening expressed by ADR in two different eras of endoscopic technology advancement.

Material and methods: We conducted a dual-center study that enrolled 24055 patients, who underwent colonoscopy as part of a national screening program. Patients were sorted into two groups according to the advancement of endoscopic equipment used for colonoscopic examination: group I - 10405 patients examined between 2004 and 2008 (standard electronic endoscopes); group II - 13650 patients examined between 2009 and 2014 (modern endoscopes). The ADR in two different eras and the impact of endoscopic novelties were determined.

Results: The ADR in group I was $29.14 \%$, in group || $31.73 \%(p<0.001)$. The overall ADR was $30.88 \%-38.80 \%$ and $25.95 \%(p<0.001)$ for the male and female patients, respectively. The mean adenoma number per colonoscopy was 0.366 (95\% Cl: $0.357-0.375 ; p<0.001), 0.337(0.321-0.352)$ and 0.380 (0.369-0.392) for patients in group I and group II, respectively.

Conclusions: Our study shows that technological innovation, novel endoscopy devices and diagnostic techniques improve the quality in CRC screening by increasing the ADR. However, we need to determine which of the technologies are supreme to achieve excellence in colorectal cancer screening.
\end{abstract}

Key words: cancer, adenoma, screening, technology, quality, colorectal, endoscopy, detection, rate, adenoma detection rate.

\section{Introduction}

Colorectal cancer (CRC) is the third most common cancer worldwide and the second most common in Europe and the United States. It constitutes approximately $10 \%$ of all cancers observed in men and women [1-3]. Over $90 \%$ of CRC cases follow an adenoma-to-cancer sequence

\author{
Corresponding author: \\ Maciej Matyja MD \\ $2^{\text {nd }}$ Department of \\ General Surgery \\ Jagiellonian University \\ Medical College \\ 21 Kopernika St \\ 31-501 Krakow, Poland \\ Phone: +48 600062103 \\ E-mail: maciek@medicina.pl
}


over many years [4]. Colorectal cancer screening has been successful in reducing the incidence and mortality of CRC by increasing the proportion diagnosed at an early stage and facilitating removal of pre-neoplastic lesions [5]. Colonoscopy is currently the preferred method for screening, decreasing the incidence of CRC by up to $80 \%[6,7]$. This beneficial effect is strongly associated with the adenoma detection rate (ADR), which is the single most important quality surrogate for screening colonoscopy. The definition of ADR suggested by the English Bowel Cancer Screening Programme is the number of colonoscopies at which one or more histologically confirmed adenomas is found divided by the total number of colonoscopies performed. According to the most recent European Society of Gastrointestinal Endoscopy (ESGE) recommendations, ADR should be at the minimum level of $25 \%$. The goal of the modern colonoscopy quality improvement is to reduce the operator dependence, and generally to move low-level performers toward high-end performance as rapidly as possible.

Poor cecal intubation rate (CIR) correlates with a low adenoma detection rate, and it is closely associated with an increased risk of post-colonoscopy colorectal cancer (PCCRC). Within recent years different endoscopic imaging techniques have been introduced to improve the quality of colonoscopy and CRC screening. We have witnessed the transition from fiberscopes to videoscopes, which already has significantly increased the diagnostic capability of endoscopes. Following the introduction of videoscopes, the structure of the endoscopes has been changed nowadays. Responsive insertion technology (RIT) combines three technologies, passive bending (PB), highforce transmission (HFT), and variable stiffness, to facilitate the feasibility of the examination, increasing the CIR, and increasing the patient's comfort. The new endoscopes also include narrow band imaging (NBI), near focus (NF) and magnetic endoscopic imaging (MEI) - novelties that are supposed to reduce the adenoma miss rate.

Our aim was to evaluate the quality of colonoscopy expressed by ADR in two different eras of endoscopic technology advancement.

\section{Material and methods}

We conducted a retrospective dual-center study in the $2^{\text {nd }}$ Department of Surgery, Jagiellonian University Medical College and the Specialist Diagnostic and Therapeutic Center "Medicina" in Krakow, Poland. The study was approved by the local ethics committee and conducted in accordance with the principles of the Declaration of Helsinki (KBN no. 122.6120.36.2016).

\section{Patients}

We selected 24055 patients aged 40-65 who underwent colonoscopy screening between January 2000 and December 2014 (as part of a national colorectal cancer screening program, which was financed by the Polish Ministry of Health). Patients with a prior history of abdominopelvic surgery, inflammatory bowel disease, active malignancy, and a high anesthetic risk (ASA IV) were excluded from the study. All patients were pre-evaluated before the examination and written informed consent for the procedure was obtained. Bowel preparation was accomplished using verbal and written information. Patients were informed to take a liquid propulsive agent (i.e., $420 \mathrm{~g}$ of polyethylene glycol (PEG) in 4 I of water) in the evening prior to the procedure for morning patients and a split-dose regimen for those in the afternoon schedule.

\section{Setting}

We used Olympus series colonoscopes (Olympus Optical Co. Ltd, Tokyo, Japan). Patients were sorted into two groups according to the endoscopic equipment used for colonoscopic examination.

Group I included 10405 patients examined between 2004 and 2008. This era encompasses the use of electronic endoscopes with a standard resolution (CF-Q145, CF-Q165, and CF-Q180).

Between 2009 and 2014, we performed 13650 colonoscopies using the CF-HQ190L (group II). This was the era of endoscopes with a high-definition resolution, magnetic scope guide, responsive insertion technology (RIT) and narrow band imaging (NBI) with dual focus two-stage optical lens technology (Table I).

Patients' preoperative characteristics including demographics, body mass index (BMI), family history of malignancy and significant comorbidities were determined.

\section{Outcome}

Ten experienced endoscopists conducted the procedures, each having independently performed over 1000 colonoscopies, certified by the Polish Society of Surgeons. The ADR was determined as the number of colonoscopies in which one or more histologically confirmed adenomas were found divided by the total number of colonoscopies performed. We compared the adenoma detection rate (ADR) and mean adenoma number per colonoscopy in two successive eras of endoscopic technological development according to the series of the endoscope used. We compared the procedures per room ratio (PPR a parameter that describes the approximate capacity of procedures per room, representing the mean number of procedures done daily in one 
Table I. Parameters of endoscopes used in the study

\begin{tabular}{|c|}
\hline Endoscopes used in group I (2004-2008) \\
\hline $\begin{array}{l}\text { Olympus CF-Q145: } \\
\text { - Diameter: } 12.8 \mathrm{~mm} \\
\text { - Working length: } 168 \mathrm{~cm} \\
\text { - Instrument channel: } 3.7 \mathrm{~mm} \\
\text { - Field of view: } 140^{\circ} \\
\text { - Angulation range: up: } 180 \text {, down: } 180 \text {, right: } 160 \text {, } \\
\text { left } 160\end{array}$ \\
\hline $\begin{array}{l}\text { Olympus CF-Q165: } \\
\text { - Diameter: } 12.8 \mathrm{~mm} \\
\text { - Working length: } 168 \mathrm{~cm} \\
\text { - Instrument channel: } 3.7 \mathrm{~mm} \\
\text { - Field of view: } 140^{\circ} \\
\text { - Angulation range: up: } 180 \text {, down: } 180 \text {, right: } 160 \text {, } \\
\text { left } 160\end{array}$ \\
\hline $\begin{array}{l}\text { Olympus CF-Q180: } \\
\text { - Diameter: } 12.8 \mathrm{~mm} \\
\text { - Working length: } 168 \mathrm{~cm} \\
\text { - Instrument channel: } 3.7 \mathrm{~mm} \\
\text { - Field of view: } 170^{\circ} \\
\text { - Angulation range: up: } 180 \text {, down: } 180 \text {, right: } 160 \text {, } \\
\text { left } 160 \\
\text { - Features: variable stiffness technology }\end{array}$ \\
\hline Endoscopes used in group II (2009-2014) \\
\hline $\begin{array}{l}\text { Olympus CF-HQ190L: } \\
\text { - Diameter: } 12.8 \mathrm{~mm} \\
\text { - Working length: } 168 \mathrm{~cm} \\
\text { - Instrument channel: } 3.7 \mathrm{~mm} \\
\text { - Field of view: } 170^{\circ} \text {, near } 160^{\circ} \\
\text { - Angulation range: up: } 180 \text {, down: } 180 \text {, right: } 160 \text {, } \\
\text { left } 160 \\
\text { - Features: variable stiffness technology, narrow band } \\
\text { imaging (NBI), responsive insertion technology (RIT), } \\
\text { scope guide, high definition (HD) }(1280 \times 1024 \text { pixels) }\end{array}$ \\
\hline
\end{tabular}

colonoscopy office). Other endpoints of the study influencing the ADR were analyzed: completeness of examination, bowel preparation assessment (5-point scale), and patient tolerance for examination (4-point scale). Pathological results were also presented.

\section{Statistical analysis}

All data were analyzed with StatSoft Statistica v.12.5 (StatSoft Inc, Tulsa, Oklahoma, USA). The results are presented as mean \pm standard deviation (SD), or median and interquartile range (IQR), when appropriate. The study of categorical variables used Pearson's $\chi^{2}$ test, or $\chi^{2}$ with Yates correction when appropriate. The Shapiro-Wilk test was used to check for normal distribution of data. Quantitative data were analyzed with Student's $t$-test (for normally distributed data) or the Mann-Whitney test (for non-normally distributed data). Univariate and multivariate logistic regression models were built including continuous and categorical variables. Results were considered sta- tistically significant when the $p$-value was found to be less than 0.05 .

\section{Results}

We observed no difference between the groups regarding sex and age ( $p=0.790$ and 0.404 , respectively). Body mass index was slightly higher in group II ( $p<0.001)$. Family history of malignancy was more prevalent in group II (43\% vs. $41.18 \%$, $p=0.010)$. Patients in this group had more significant comorbidities than in group I $(21.87 \%$ vs. $8.89 \%, p<0.001)$. Complete colonoscopies were performed more frequently in group II (96.68\% vs. $93.73 \%, p<0.001)$ and the adenoma detection rate was higher in group II (31.73\% vs. $29.14 \%$, $p<0.001)$ along with mean adenoma number per colonoscopy $(p<0.001)$. Procedures per room ratio (PPR) was comparable $(p=0.088)$. Patients in groups I and II differed slightly, yet statistically significantly, in terms of bowel preparation and tolerance of examination $(p<0.001)$. Bowel preparation assessment was classified as follows: 1 - poor, 2 - substandard, 3 - adequate, 4 - good, 5 - excellent. Patients' tolerance of colonoscopy was described as follows: 1 - severe discomfort, 2 - moderate discomfort, 3 - mild discomfort, 4- no or minimal discomfort. Basic characteristics and comparison between group I and group II are presented in Table II.

Table III presents univariate logistic regression analysis of influence of selected factors on completeness of examinations. Significant factors were patients' sex, age, BMI, bowel preparation, tolerance and examination performed in group II. They were included in multivariate logistic regression in Table IV. Multivariate logistic regression analysis of the influence of selected factors on completeness of examinations revealed that patients' sex, BMI, bowel preparation, tolerance and colonoscopy performed in the era of modern endoscopes were significant independent factors that resulted in completeness of examinations.

Univariate logistic regression analysis of the influence of selected factors on the adenoma detection rate (ADR) is presented in Table V. Male sex, age, BMI, bowel preparation, completeness of examinations, patient's tolerance for examination and colonoscopies performed in group II increased ADR. Then significant factors were included in the multivariate logistic regression analysis presented in Table VI: male sex, age, BMI, bowel preparation, completeness of examinations and examinations performed in the modern endoscope era (group II) increased ADR as independent factors.

The overall ADR was $30.88-38.80 \%$ and $25.95 \%$ for the male and female patients, respectively. The mean adenoma number per colonoscopy was 0.366 (95\% Cl: 0.357-0.375) - 0.483 (0.466- 
Table II. Comparison between groups

\begin{tabular}{|c|c|c|c|c|}
\hline Parameter & All & Group I & Group II & $P$-value \\
\hline Sex M/F, $n(\%)$ & $\begin{array}{c}9007 / 13841 \\
(39 \% / 61 \%) \\
\end{array}$ & $\begin{array}{l}2881 / 4404 \\
(40 \% / 60 \%)\end{array}$ & $\begin{array}{l}6126 / 9437 \\
(39 \% / 61 \%)\end{array}$ & 0.790 \\
\hline Age, mean \pm SD [years] & $54 \pm 7$ & $54 \pm 6$ & $54 \pm 7$ & 0.404 \\
\hline BMI, mean $\pm \mathrm{SD}\left[\mathrm{kg} / \mathrm{m}^{2}\right]$ & $26.87 \pm 4.74$ & $26.56 \pm 3.9$ & $26.97 \pm 4.97$ & $<0.001$ \\
\hline Malignancy in family history, $n(\%)$ & $9692(42.42)$ & $3000(41.18)$ & $6692(43.00)$ & 0.010 \\
\hline Significant comorbidity, $n$ (\%) & $4051(17.73)$ & $648(8.89)$ & $3403(21.87)$ & $<0.001$ \\
\hline Full/incomplete examinations, $n(\%)$ & $\begin{array}{l}21875 / 973 \\
(95.74 / 4.26)\end{array}$ & $\begin{array}{c}6828 / 457 \\
(93.73 / 6.27)\end{array}$ & $\begin{array}{l}15047 / 516 \\
(96.68 / 3.32)\end{array}$ & $<0.001$ \\
\hline PPR & $10.29 \pm 6.88$ & $9.95 \pm 6.22$ & $10.46 \pm 7.17$ & 0.088 \\
\hline Adenoma detection rate - ADR (\%) & 30.88 & 29.14 & 31.73 & $<0.001$ \\
\hline $\begin{array}{l}\text { Adenoma number per colonoscopy, } \\
\text { mean } \pm \text { SD }(95 \% \mathrm{Cl})\end{array}$ & $\begin{array}{l}0.366 \pm 0.715 \\
(0.357-0.375)\end{array}$ & $\begin{array}{l}0.337 \pm 0.683 \\
(0.321-0.352)\end{array}$ & $\begin{array}{l}0.380 \pm 0.728 \\
(0.369-0.392)\end{array}$ & $<0.001$ \\
\hline \multicolumn{5}{|l|}{ Bowel preparation assessment ${ }^{\star}, n(\%)$ : } \\
\hline 5 & $20726(90.71)$ & $6824(93.67)$ & $13902(89.27)$ & \multirow[t]{5}{*}{$<0.001$} \\
\hline 4 & $377(1.65)$ & $86(1.18)$ & $291(1.87)$ & \\
\hline 3 & $712(3.12)$ & $266(3.65)$ & $446(2.87)$ & \\
\hline 2 & $271(1.19)$ & $90(1.24)$ & $181(1.16)$ & \\
\hline 1 & $67(0.29)$ & $19(0.26)$ & $48(0.31)$ & \\
\hline \multicolumn{5}{|l|}{ Patient tolerance for exam*, $n(\%)$ : } \\
\hline 4 & $21838(95.58)$ & $6988(95.92)$ & $14850(95.42)$ & \multirow[t]{4}{*}{$<0.001$} \\
\hline 3 & $305(1.33)$ & $117(1.61)$ & $188(1.21)$ & \\
\hline 2 & $265(1.16)$ & $63(0.86)$ & $202(1.30)$ & \\
\hline 1 & $305(1.33)$ & $117(1.61)$ & $188(1.21)$ & \\
\hline
\end{tabular}

$P P R$ - procedures per room, parameter that describes approximate capacity of procedures per room, representing mean number of procedures done daily in one colonoscopy office. *Bowel preparation assessment classification: 1 - poor, 2 - substandard, 3 - adequate, 4 - good, 5 - excellent. ${ }^{* *}$ Patient tolerance of colonoscopy classification: 1 - severe discomfort, 2 - moderate discomfort, 3 - mild discomfort, 4- no or minimal discomfort.

Table III. Univariate logistic regression analysis of influence of selected factors on completeness of examinations

\begin{tabular}{|c|c|c|c|}
\hline Parameter & OR & $95 \% \mathrm{Cl}$ & $P$-value \\
\hline Sex, M vs. F & 0.43 & $0.37-0.51$ & $<0.001$ \\
\hline Age, with every year & 0.99 & $0.98-0.99$ & 0.049 \\
\hline BMI, with every $1 \mathrm{~kg} / \mathrm{m}^{2}$ & 0.93 & $0.91-0.95$ & $<0.001$ \\
\hline Significant comorbidity & 1.05 & $0.47-2.34$ & 0.905 \\
\hline Bowel preparation assessment, with every grade higher & 1.95 & $1.88-2.02$ & $<0.001$ \\
\hline Patient tolerance for exam, with every grade higher & 4.52 & $4.19-4.87$ & $<0.001$ \\
\hline Group 1 vs. 2 & 1.95 & $1.71-2.22$ & $<0.001$ \\
\hline
\end{tabular}

$O R$ - odds ratio, $\mathrm{Cl}$ - confidence interval.

$0.500)$ and $0.290(0.280-0.301)$ for the male and female patients, respectively.

Table VII presents the adenoma detection rate in relation to specific factors that influenced ADR in the logistic regression model.
Tables VIII and IX present comparisons of histopathological findings respectively in distal and proximal colon between groups with $p$-values of inter-group comparisons. 
Maciej Matyja, Artur Pasternak, Mirosław Szura, Michał Wysocki, Michał Pędziwiatr, Kazimierz Rembiasz

Table IV. Multivariate logistic regression analysis of influence of selected factors on completeness of examinations

\begin{tabular}{|lllc|}
\hline Parameter & OR & $95 \% \mathrm{Cl}$ & $P$-value \\
\hline Sex, M vs. F & 0.59 & $0.49-0.71$ & $<0.001$ \\
\hline BMI, with every $1 \mathrm{~kg} / \mathrm{m}^{2}$ & 0.96 & $0.94-0.98$ & $<0.001$ \\
\hline Bowel preparation assessment, with every grade higher & 2.11 & $1.94-2.29$ & $<0.001$ \\
\hline Patient tolerance for exam, with every grade higher & 4.67 & $4.28-5.10$ & $<0.001$ \\
\hline Group 1 vs. 2 & 1.91 & $1.60-2.27$ & $<0.001$ \\
\hline
\end{tabular}

$O R$ - odds ratio, $\mathrm{Cl}$ - confidence interval.

Table V. Univariate logistic regression analysis of influence of selected factors on ADR

\begin{tabular}{|c|c|c|c|}
\hline Parameter & OR & $95 \% \mathrm{Cl}$ & $P$-value \\
\hline Sex, F vs. M & 1.82 & $1.69-1.92$ & $<0.001$ \\
\hline Age, with every year & 1.03 & $1.02-1.04$ & $<0.001$ \\
\hline BMI, with every $1 \mathrm{~kg} / \mathrm{m}^{2}$ & 1.03 & $1.02-1.04$ & $<0.001$ \\
\hline Significant comorbidity & 1.06 & $0.98-1.15$ & 0.124 \\
\hline Bowel preparation assessment, with every grade higher & 1.19 & $1.11-1.27$ & $<0.001$ \\
\hline Patient tolerance for exam, with every grade higher & 1.31 & $1.20-1.43$ & $<0.001$ \\
\hline Completeness of examinations & 2.09 & $1.73-2.53$ & $<0.001$ \\
\hline Group 1 vs. 2 & 1.13 & $1.05-1.22$ & 0.001 \\
\hline
\end{tabular}

OR - odds ratio, $\mathrm{Cl}$ - confidence interval.

Table VI. Multivariate logistic regression analysis of influence of selected factors on ADR

\begin{tabular}{|lccc|}
\hline Parameter & OR & $95 \% \mathrm{Cl}$-value & $<0.001$ \\
\hline Sex, F vs. M & 1.82 & $1.69-1.96$ & $<0.001$ \\
\hline Age, with every year & 1.03 & $1.02-1.04$ & $<0.001$ \\
\hline BMI, with every 1 kg/m² & 1.02 & $1.01-1.03$ & $1.09-1.26$ \\
\hline Bowel preparation assessment, with every grade higher & 1.17 & $0.95-1.18$ & 0.271 \\
\hline Patient tolerance for exam, with every grade higher & 1.06 & $1.41-2.26$ & $<0.001$ \\
\hline Completeness of examinations & 1.79 & $1.04-1.22$ & 0.004 \\
\hline Group 1 vs. 2 & 1.13 & & $<$ \\
\hline
\end{tabular}

$O R$ - odds ratio, $\mathrm{Cl}$ - confidence interval.

\section{Discussion}

The single most important outcome to measure the effectiveness of colonoscopy is the ADR, since it is associated with the future risk of CRC occurrence and mortality. Physicians performing screening colonoscopies with ADR below $20 \%$ are more likely to have patients subsequently presenting interval cancer [8].

Our results have confirmed some particular circumstances that without a doubt should be maintained to keep the quality of the examinations at the highest possible level. Effective bowel cleansing is one of them. The better the bowel preparation is, the more precise is detection of preneoplastic lesions and the easier is cecal intubation.
Poor cleansing of the bowel is associated with prolonged procedures and low ADR. There is heterogeneity among the studies concerning bowel cleansing as to whether split or non-split preparation is more effective. However, tolerance of high volumes of polyethylene glycol (PEG) solution may be low. Splitting the dose may improve it [9]. Authors are now also focusing on the timing of bowel cleansing. The outcome of cleansing appears to be efficient when the examination is commenced within hours of the bowel preparation [10]. The bowel cleansing in our study met the criteria of the European Society of Gastrointestinal Endoscopy, according to which no more than $10 \%$ of the examinations should need to be repeated due to inadequate bowel preparation. 
Patient-related aspects also have an impact on ADR. Obesity is an independent risk factor of adenoma occurrence. There is a debate concerning body weight and the technical struggle in reaching the cecum during colonoscopy. There is evidence suggesting that both low and high BMI patients are technically demanding for a physician performing the examination [11]. Obesity is also associated with poor bowel preparation, which can subsequently lead to a difficult and prolonged colonoscopy. Our study has revealed that a higher BMI was a factor associated with statistically significantly higher ADR and a higher cecal intubation rate $(\mathrm{CIR})$. It might be due to the low muscle content of a low-BMI patient that may predispose to loop formation and patient intolerance, which leads to unsuccessful colonoscopy. There are studies which revealed that the number of loops formed during the insertion of the endoscope in low-BMI patients is higher than that in obese patients [12].

The ADR varies between men and women. Adenomas are more common in men, which explains our outcome that male sex is an independent factor leading to higher ADR. The American Society for Gastrointestinal Endoscopy (ASGE) recommendations propose that adenomas should be detected in more than $25 \%$ of asymptomatic male individuals ( $>50$ years) and in more than $15 \%$ of asymptomatic female individuals ( $>50$ years) at first. According to studies based on large populations of patients, factors associated with completion of the colonoscopy without sedation include male sex. That explains the higher cecal intubation rate among males in our study [13]. ADR as well as the advanced cancer detection also increases with age. Both men and women with each decade of life after 50 have a statistically higher ADR [14].

Several studies have shown that even certified colonoscopists exhibit variation in the adenoma detection rate. The difference in detecting serrated lesions is even greater than for conventional adenomas. It demonstrates that colonoscopy is a highly operator-dependent procedure $[15,16]$. That is why training in differentiation skills is essential.

The benefit of knowing our own ADR may also motivate endoscopic quality improvement, as it has been shown in several interventional studies with the implementation of scheduled personalized ADR report cards $[17,18]$. It has been confirmed in recent studies, including a meta-analysis, where patients were undergoing same-day, back-to-back (tandem) colonoscopies, that especially in the right colon polyps are more likely to be missed $[19,20]$. Of course failure to reach the cecum leads to low ADR in the right colon as a consequence of excessive loop formation or failure to traverse angulated, fixed, or strictured
Table VII. Comparison of ADR in selected parameters

\begin{tabular}{|lcc|}
\hline Parameter & ADR (\%) & $P$-value \\
\hline Sex, F vs. M & $25.95 / 38.80$ & $<0.001$ \\
\hline Age [years]: & & \\
\hline $50-55$ & 27.82 & \\
\hline $56-60$ & 32.08 & \\
\hline $61-65$ & $33.43 \%$ &
\end{tabular}

BMI $\left[\mathrm{kg} / \mathrm{m}^{2}\right]$ :

\begin{tabular}{lcc}
\hline$<25$ & 28.17 & $<0.001$ \\
\cline { 1 - 2 } $25-30$ & 31.71 & \\
\cline { 1 - 2 } $30-35$ & 34.60 & \\
\hline 35 & 36.82 & 0.132 \\
$\begin{array}{l}\text { Significant comorbidity, } \\
\text { Yes/no }\end{array}$ & $31.96 / 30.62$ & \\
$\begin{array}{l}\text { Malignancy in family, } \\
\text { Yes/no }\end{array}$ & $31.09 / 30.82$ & 0.751 \\
\hline
\end{tabular}

Yes/no

Bowel preparation assessment*:

\begin{tabular}{ll}
\hline 5 & 32.26 \\
\hline 4 & 23.86 \\
\hline 3 & 23.65 \\
\hline 2 & 30.10 \\
\hline 1 & 11.54
\end{tabular}

Patient tolerance for exam**:

\begin{tabular}{|ccc|}
\hline 4 & 31.32 & $<0.001$ \\
\cline { 1 - 2 } 3 & 22.19 & \\
\cline { 1 - 2 } 2 & 21.13 & \\
\cline { 1 - 2 } $\begin{array}{l}\text { Complete vs. incomplete } \\
\text { examination }\end{array}$ & $31.47 / 18.01$ & $<0.001$ \\
\cline { 1 - 2 } Group 1 vs. 2 & $29.14 / 31.73$ & 0.001 \\
\hline
\end{tabular}

*Bowel preparation assessment classification: 1 - poor, 2 substandard, 3 - adequate, 4 - good, 5 - excellent. ${ }^{* *}$ Patient tolerance of colonoscopy classification: 1 - severe discomfort, 2 - moderate discomfort, 3 - mild discomfort, 4-no or minimal discomfort.

sigmoids (most commonly among female patients with prior gynecological surgery and patients with advanced diverticular disease). Even if the cecum is intubated successfully, there are factors increasing the adenoma miss rate such as localization behind the folds and flat lesions [21, 22].

Using an effective technique means performing endoscopy with a withdrawal time allowing a physician to keep his ADR level high. There is a strong association of detection of precancerous lesions with withdrawal time. There are studies showing 
Maciej Matyja, Artur Pasternak, Mirosław Szura, Michał Wysocki, Michał Pędziwiatr, Kazimierz Rembiasz

Table VIII. Comparison of histopathological findings in distal colon between groups

\begin{tabular}{|c|c|c|c|c|}
\hline Parameter & All & Group I & Group II & $P$-value \\
\hline $\begin{array}{l}\text { Total number of exams with samples for } \\
\text { pathological exam }\end{array}$ & $3501(15.32 \%)$ & $1187(16.29 \%)$ & 2337 (15.02\%) & 0.013 \\
\hline Non-neoplastic lesions & $1509(6.60 \%)$ & $559(7.67 \%)$ & $950(6.10 \%)$ & $<0.001$ \\
\hline Hyperplastic polyp & $422(1.85 \%)$ & $141(1.94 \%)$ & $281(1.81 \%)$ & 0.497 \\
\hline Benign non-epithelial neoplasm & $123(0.54 \%)$ & $36(0.49 \%)$ & $87(0.56 \%)$ & 0.532 \\
\hline $1-2$ Tubular adenomas $<10 \mathrm{~mm}$ & $1059(4.63 \%)$ & $283(3.88 \%)$ & $776(4.99 \%)$ & $<0.001$ \\
\hline 3-4 Tubular adenomas $<10 \mathrm{~mm}$ & $29(0.13 \%)$ & $5(0.07 \%)$ & $24(0.15 \%)$ & 0.135 \\
\hline$\geq 5$ Tubular adenomas $<10 \mathrm{~mm}$ & $3(0.01 \%)$ & 0 & $3(0.02 \%)$ & - \\
\hline Tubular adenoma $\geq 10 \mathrm{~mm}$ & $97(0.42 \%)$ & $38(0.52 \%)$ & $59(0.38 \%)$ & 0.122 \\
\hline $1-2$ Tubular-villous adenomas $<10 \mathrm{~mm}$ & $58(0.25 \%)$ & $24(0.33 \%)$ & $34(0.22 \%)$ & 0.120 \\
\hline$\geq 5$ Tubular-villous adenomas $<10 \mathrm{~mm}$ & $1(<0.01 \%)$ & $1(0.01 \%)$ & 0 & - \\
\hline Tubular-villous adenoma $\geq 10 \mathrm{~mm}$ & $34(0.15 \%)$ & $16(0.22 \%)$ & $18(0.12 \%)$ & 0.057 \\
\hline Villous adenoma $<10 \mathrm{~mm}$ & $4(0.02 \%)$ & $2(0.03 \%)$ & $2(0.01 \%)$ & 0.810 \\
\hline Villous adenoma $\geq 10 \mathrm{~mm}$ & $3(0.01 \%)$ & $3(0.04 \%)$ & 0 & - \\
\hline Polyp with high grade dysplasia < $10 \mathrm{~mm}$ & $54(0.24 \%)$ & $22(0.30 \%)$ & $32(0.21 \%)$ & 0.211 \\
\hline Polyp with high grade dysplasia $\geq 10 \mathrm{~mm}$ & $28(0.12 \%)$ & $8(0.11 \%)$ & $20(0.13 \%)$ & 0.862 \\
\hline Invasive adenocarcinoma in polyp & $6(0.03 \%)$ & $3(0.04 \%)$ & $3(0.02 \%)$ & 0.607 \\
\hline Non-epithelial malignant neoplasm & $1(<0.01 \%)$ & 0 & $1(0.01 \%)$ & - \\
\hline Macroscopic adenocarcinoma & $70(0.31 \%)$ & $23(0.32 \%)$ & $47(0.30 \%)$ & 0.861 \\
\hline
\end{tabular}

Table IX. Comparison of histopathological findings in proximal colon between groups

\begin{tabular}{|c|c|c|c|c|}
\hline Parameter & All & Group I & Group II & $P$-value \\
\hline $\begin{array}{l}\text { Total number of exams with samples for } \\
\text { pathological exam }\end{array}$ & $12943(56.65 \%)$ & $4618(63.39 \%)$ & $8325(53.49 \%)$ & $<0.001$ \\
\hline Non-neoplastic lesions & $8331(36.46 \%)$ & $3086(42.36 \%)$ & $5245(33.70 \%)$ & $<0.001$ \\
\hline Hyperplastic polyp & $1957(8.57 \%)$ & $658(9.03 \%)$ & $1299(8.35 \%)$ & 0.084 \\
\hline Benign non-epithelial neoplasm & $44(0.60 \%)$ & $17(0.23 \%)$ & $27(0.17 \%)$ & 0.336 \\
\hline $1-2$ Tubular adenomas $<10 \mathrm{~mm}$ & $1483(20.36 \%)$ & $413(5.67 \%)$ & $1070(6.88 \%)$ & 0.006 \\
\hline 3-4 Tubular adenomas $<10 \mathrm{~mm}$ & $44(0.19 \%)$ & $13(0.18 \%)$ & $31(0.20 \%)$ & 0.739 \\
\hline$\geq 5$ Tubular adenomas $<10 \mathrm{~mm}$ & $11(0.05 \%)$ & $3(0.04 \%)$ & $8(0.01 \%)$ & 0.996 \\
\hline Tubular adenoma $\geq 10 \mathrm{~mm}$ & $286(1.25 \%)$ & $119(1.63 \%)$ & $167(1.07 \%)$ & $<0.001$ \\
\hline $1-2$ Tubular-villous adenomas < $10 \mathrm{~mm}$ & $148(0.65 \%)$ & $64(0.88 \%)$ & $84(0.54 \%)$ & 0.003 \\
\hline 3-4 Tubular-villous adenomas < $10 \mathrm{~mm}$ & $4(0.02 \%)$ & $3(0.04 \%)$ & $1(0.01 \%)$ & 0.189 \\
\hline Tubular-villous adenoma $\geq 10 \mathrm{~mm}$ & $107(0.47 \%)$ & $52(0.71 \%)$ & $55(0.35 \%)$ & $<0.001$ \\
\hline Villous adenoma $<10 \mathrm{~mm}$ & $4(0.02 \%)$ & $3(0.04 \%)$ & $1(0.01 \%)$ & 0.189 \\
\hline Villous adenoma $\geq 10 \mathrm{~mm}$ & $20(0.09 \%)$ & $13(0.18 \%)$ & $7(0.04 \%)$ & 0.003 \\
\hline Polyp with high grade dysplasia < $10 \mathrm{~mm}$ & $108(0.47 \%)$ & $40(0.55 \%)$ & $68(0.44 \%)$ & 0.250 \\
\hline Polyp with high grade dysplasia $\geq 10 \mathrm{~mm}$ & $125(0.55 \%)$ & $37(0.51 \%)$ & $88(0.57 \%)$ & 0.583 \\
\hline Invasive adenocarcinoma in polyp & $25(0.11 \%)$ & $9(0.12 \%)$ & $16(0.10 \%)$ & 0.659 \\
\hline Non-epithelial malignant neoplasm & $5(0.02 \%)$ & $1(0.01 \%)$ & $4(0.03 \%)$ & 0.928 \\
\hline Macroscopic adenocarcinoma & $241(1.05 \%)$ & $87(1.19 \%)$ & $154(0.99 \%)$ & 0.158 \\
\hline
\end{tabular}


a linear correlation between ADR and withdrawal time, proving that a 6-minute withdrawal time is crucial to maintain the quality of the examination $[23,24]$.

The role of modern colonoscopy is to improve the quality by reducing the operator dependence. Within recent years different types of endoscopic imaging techniques have been introduced to improve the quality in colonoscopy and as a consequence the colorectal cancer screening. Advanced endoscopic imaging is revolutionizing our current methods to diagnose and treat colorectal lesions.

One of the technologies that has become standard in modern endoscopy is high definition (HD). High definition endoscopes have more pixels than standard definition (SD). Improved image quality should improve lesion detection and recognition. High definition not only helps to visualize lesions during a screening colonoscopy, but it also enhances evaluation of post-polypectomy scars at follow-up. A meta-analysis suggested that the implementation of $\mathrm{HD}$ produces a $2 \%$ to $4 \%$ gain in the ADR [25]. In our study ADR in successive eras of endoscopic technological development has risen. The difference in ADR between the analyzed eras is $2.59 \%$, which is an acceptable level according to the literature.

Another optical enhancement technology present in modern endoscopes is filter technology that uses narrow red-green-blue light bands, i.e. narrow band imaging (NBI), to enhance micro-vessel architecture. There are randomized controlled trials (RCTs) showing the improvement in ADR with the use of $\mathrm{NBI}$ compared to standard endoscopies. There is also one study suggesting that NBI may improve the learning curve for detecting flat lesions $[26,27]$. Initial studies show that this technology has potential to improve ADR, but we definitely need further investigations. In our study we cannot determine what the real influence on ADR in group II was. Not every report contained the Kudo classification describing the found lesion. However, it was possible to use the NBI whenever the physician performing endoscopy had diagnostic doubts.

In our study we performed a multivariate logistic regression analysis of the influence of selected factors on ADR, which showed that patients' tolerance is one of the crucial elements. The modern endoscopes that we used in our study are equipped with tools that increase the tolerance of the patients. The variable stiffness of the endoscope and responsive insertion technology (RIT) are features simplifying endoscope insertion and reducing the discomfort and pain during the examination. Undesired loops are reduced when the RIT endoscope is used, because of the secondary bending section of the endoscope and its flexibil- ity. In conventional colonoscopes, when the scope passes through a sharp flexure in the colon, the force applied by the physician when inserting the scope can sometimes directly push up the wall of the colon because the distal end of the scope bends with a small radius (the so-called stick phenomenon). The bending function is useful for preventing the stick phenomenon, which causes severe pain for patients during colonoscopic insertion in colonic flexures [28, 29]. Reduction of loop formation and auxiliary maneuvers when using RIT reduce the patients' discomfort, leading to higher ADR.

Another technology that has an impact on patients' tolerance is magnetic endoscopic imaging (MEI) commercialized by Olympus as ScopeGuide (Olympus, Tokyo, Japan). Magnetic endoscopic imaging is a non-radiographic imaging technique capable of displaying real-time three-dimensional images of the colonoscope shaft within the abdominal cavity [30]. The main advantage is the possibility to locate the lesions precisely. However, there are RCTs confirming that use of $\mathrm{MEI}$ during colonoscopy has the potential to ease cecal intubation, and reduce patient discomfort and dependence on sedation [31]. Also the MEI system appears to be beneficial for inexperienced endoscopists, and it increases the cecal intubation rate. The technology helps to reduce the number of attempts to straighten loops and the duration of looping. However, experienced endoscopists are likely able to recognize and resolve loops quickly without the need for MEI visualization [32].

Colonoscopy is considered to be a gold standard for CRC screening. However, we still have a lot of work to do, especially considering the adenoma miss rate in the right colon. Many lesions are still missed because of the inability to visualize flat lesions and those located behind the fold. A perfect device should be ergonomic, and effective in its results and costs $[33,34]$. According to our experience technologies such as HD, NBI, RIT and MEI meet the above-mentioned criteria and enhance the quality of screening endoscopy. There are several technologies present on the market, such as Full Spectrum Endoscopy (FUSE) and devices fixed to the colonoscope tip for the purpose of flattening folds, including a short cap or hood, Endocuff, Endocuff Vision, and Endoring. Our experience with those technologies is initial. Hence, we need more date to determine whether they can improve ADR. So far the data are mixed with regard to their efficacy.

In conclusion, there has been a technological revolution in endoscopy since the beginning of our study in 2004. We showed that technological innovations, novel endoscopy devices and diagnostic techniques as well as patient-related fac- 
tors significantly improve the quality of colorectal cancer screening by increasing the adenoma detection rate. Endoscopes of the new era have great potential. However, in the future, we need to determine and standardize which of the technologies are supreme to achieve excellence in colorectal cancer screening.

\section{Acknowledgments}

The research project reported in this manuscript has been fully sponsored by the authors.

\section{Conflict of interest}

The authors declare no conflict of interest.

\section{References}

1. Ferlay J, Soerjomataram II, Dikshit R, et al. Cancer incidence and mortality worldwide: sources, methods and major patterns in GLOBOCAN 2012. Int I Cancer 2014; 136: E359-86.

2. Zhang K, Chen Y, Huang X, et al. Expression and clinical significance of cytochrome $c$ oxidase subunit IV in colorectal cancer patients. Arch Med Sci 2016; 12: 68-77.

3. Çetin D, Yildirim M, Yakan S, Çiyiltepe H, Aydoğan S. Effects of prognostic factors on overall and disease-free survival in patients with stage I-III colorectal cancer. Arch Med Sci Civil Dis 2016; 1: 131-8.

4. Levin B, Lieberman DA, McFarland B, et al. Screening and surveillance for the early detection of colorectal cancer and adenomatous polyps, 2008: a joint guideline from the American Cancer Society, the US Multi-Society Task Force on Colorectal Cancer, and the American College of Radiology. Gastroenterology 2008; 134: 1570-95.

5. Zhang T, Cui G, Yao Y, et al. Value of CNRIP1 promoter methylation in colorectal cancer screening and prognosis assessment and its influence on the activity of cancer cells. Arch Med Sci 2017; 13: 1281-94.

6. Qaseem A, Denberg TD, Hopkins RH Jr, et al. Screening for colorectal cancer: a guidance statement from the American College of Physicians. Ann Intern Med 2012; 156: 378-86.

7. Rex DK, Johnson DA, Anderson JC, Schoenfeld PS, Burke CA, Inadomi JM. American College of Gastroenterology guidelines for colorectal cancer screening 2009 [corrected]. Am J Gastroenterol 2009; 104: 739-50.

8. Kaminski MF, Regula JR, Kraszewska E, et al. Quality indicators for colonoscopy and the risk of interval cancer. N Engl J Med 2010; 362: 1795-803.

9. Belsey J, Epstein O, Heresbach D. Systematic review: oral bowel preparation for colonoscopy. Aliment Pharmacol Ther 2007; 25: 373-84.

10. Aoun E, Baki HA, Azar C, et al. A randomized single-blind trial of split-dose PEG-electrolyte solution without dietary restriction compared with whole dose PEG-electrolyte solution with dietary restriction for colonoscopy preparation. Gastrointest Endosc 2005; 62: 213-8.

11. Waye JD. Completing colonoscopy. Am J Gastroenterol 2000; 95: 2681-2.

12. Witte TN, Enns R. The difficult colonoscopy. Can J Gastroenterol 2007; 21: 487-90.

13. Gonçalves AR, Ferreira C, Marques A, et al. Assessment of quality in screening colonoscopy for colorectal cancer. Clin Exp Gastroenterol 2011; 4: 277-81.
14. Diamond SJ, Enestvedt BK, Jiang Z, et al. Adenoma detection rate increases with each decade of life after 50 years of age. Gastrointest Endosc 2011; 74: 135-40.

15. Hetzel JT, Huang CS, Coukos JA, et al. Variation in the detection of serrated polyps in an average risk colorectal cancer screening cohort. Am J Gastroenterol 2010; 105: $2656 \mathrm{e} 64$.

16. Kahi CJ, Hewett DG, Norton DL, Eckert GJ, Rex DK. Prevalence and variable detection of proximal colon serrated polyps during screening colonoscopy. Clin Gastroenterol Hepatol 2011; 9: 42-6.

17. Coe SG, Crook JE, Diehl NN, Wallace MB. An endoscopic quality improvement program improves detection of colorectal adenomas. Am J Gastroenterol 2013; 108: 219-26.

18. Wallace MB, Crook JE, Thomas CS, Staggs E, Parker L, Rex DK. Effect of an endoscopic quality improvement program on adenoma detection rates: a multicenter cluster-randomized controlled trial in a clinical practice setting (EQUIP-3). Gastrointest Endosc 2017; 85: 538-45.

19. Lakoff J, Paszat LF, Saskin R, et al. Risk of developing proximal versus distal col-orectal cancer after a negative colonoscopy: a population-based study. Clin Gastroenterol Hepatol 2008; 6: 1117-21.

20. Pabby A, Schoen RE, Weissfeld JL, et al. Analysis of colorectal cancer occurrence during surveillance colonoscopy in the dietary polyp prevention trial. Gastrointest Endosc 2005; 61: 385-91.

21. Eloubeidi MA, Wallace MB, Desmond R, Farraye FA. Female gender and other factors predictive of a limited screening flexible sigmoidoscopy examination for colorectal cancer. Am J Gastroenterol 2003; 98: 1634-9.

22. Heresbach D, Barrioz T, Lapalus MG, et al. Miss rate for colorectal neoplastic polyps: a prospective multicenter study of back-to-back video colonoscopies. Endoscopy 2008; 40: 284-90.

23. Barclay RI, Vicari JJ, Doughty AS, Johanson JF, Greenlaw RL. Colonoscopic withdrawal times and adenoma detection during screening colonoscopy. N Engl J Med 2006; 355: 2533-41.

24. Shaukat A, Rector TS, Church TR, et al. Longer withdrawal time is associated with a reduced incidence of interval cancer after screening colonoscopy. Gastroenterology 2015; 149: 952-7.

25. Subramanian V, Mannath J, Hawkey CJ, Ragunath K. High definition colonoscopy vs. standard video endoscopy for the detection of colonic polyps: a meta-analysis. Endoscopy 2011; 43: 499-505.

26. Inoue T, Murano M, Murano N, et al. Comparative study of conventional colonoscopy and pan-colonic narrow-band imaging system in the detection of neoplastic colonic polyps: a randomized, controlled trial. J Gastroenterol 2008; 43: 45-50.

27. Adler A, Pohl H, Papanikolaou IS, et al. A prospective randomised study on narrow-band imaging versus conventional colonoscopy for adenoma detection: does narrow-band imaging induce a learning effect? Gut 2008; 57: 59-64.

28. Saito $\mathrm{Y}$, Kimura H. Responsive insertion technology. Dig Endosc 2011; 23 (Suppl 1): 164-7.

29. Pasternak A, Szura M, Solecki R, et al. Impact of responsive insertion technology (RIT) on reducing discomfort during colonoscopy: randomized clinical trial. Surg Endosc 2017; 31: 2247-54.

30. Leung FW. Magnetic endoscope imaging colonoscope: a new modality for hypothesis testing in unsedated colonoscopy. Gastrointest Endosc 2012; 75: 1037-9. 
31. Hoff G, Bretthauer M, Dahler S, et al. Improvement in caecal intubation rate and pain reduction by using 3-dimensional magnetic imaging for unsedated colonoscopy: a randomized trial of patients referred for colonoscopy. Scand I Gastroenterol 2007; 42: 885-9.

32. Holme Ö, Höie O, Matre J, et al. Magnetic endoscopic imaging versus standard colonoscopy in a routine colonoscopy setting: a randomized, controlled trial. Gastrointest Endosc 2011; 73: 1215-22.

33. Rex DK. Polyp detection at colonoscopy: endoscopist and technical factors. Best Pract Res Clin Gastroenterol 2017; 31: 425-33.

34. Ishaq S, Siau K, Harrison E, et al. Technological advances for improving adenoma detection rates: the changing face of colonoscopy. Dig Liver Dis 2017; 49: 721-7. 